\title{
CORRELAÇÃO DE DADOS MORFOTECTÔNICOS E GEOMORFOGENÉTICOS NA PESQUISA DO MANTO DE ALTERAÇÃO DE ROCHA DO PLANALTO SUL-RIOGRANDENSE
}

\author{
MARIA T.G.O. SCHUCK*, NELSON A. LISBOA*, NORBERTO DANI* e VITOR HAERTEL**
}

\begin{abstract}
CORRELATION OF MORPHOTECTONIC AND GEOMORPHOGENETIC DATA IN THE ROCK-ALTERATION MANTLE RESEARCH OF SUL-RIOGRANDENSE PLATO. This paper presents procedures involving photointerpretation of aerial photographs and satellite imagery, computer digital images processing together with sub-surface data relating to the depth of the alteration mantle. The aim of this study is to search for correlations between morphotectonic and geomorphological features identified in the aerial photographs and satellite imagery with the sub-surface data. Tests performed in the Southeast Parana Basin border area are presented.
\end{abstract}

Keywords: Morphotectonic, geomorphogenesis, remote sensing, Landsat.

\begin{abstract}
RESUMO Neste artigo são apresentados procedimentos envolvendo análise visual de fotografias aéreas e de imagens de satélite, processamento em computador de imagens digitais de satélite, juntamente com dados de subsuperfície relacionados com a espessura do manto de alteração. O objetivo consiste em correlacionar feições morfotectônicas e geomorfológicas identificadas nas fotografias e em imagens com dados de subsuperfície. São apresentados os resultados dos testes realizados na borda sudeste da Bacia do Paraná.
\end{abstract}

Palavras-chaves: Morfotectônica, geomorfogênese, sensoriamento remoto, Landsat

INTRODUÇ̃̃O Este artigo visa esclarecer aspectos da continuidade lateral, espessura e segmentação do manto de alteração da porção NE do Planalto Sul-riograndense, conjugando técnicas de sensoriamento remoto com dados pontuais de campo, para esclarecer os fatores morfotectônicos e geomorfogenéticos condicionantes das atuais características espaciais desse manto de alteração de rocha.

O trabalho visa contribuir também para o esclarecimento de uma metodologia operacional, integrando conceitos e técnicas de sensoriamento remoto, geologia estrutural e geomorfologia.

LOCALIZAÇÃO Em virtude das características dos dados pontuais de espessura do manto de alteração disponíveis, foi definida como área para estudos morfotectônicos regionais o Planalto Sul-riograndense, localizado aproximadamente entre as longitudes $50^{\circ} \mathrm{W}$ e $52^{\circ} \mathrm{W}$ e as latitudes $28^{\circ} \mathrm{S}$ e $29^{\circ} 30^{\prime} \mathrm{S}$, borda sudeste da Bacia do Paraná.

MATERIAIS E MÉTODOS Para atingir os objetivos desta investigação, foi utilizada uma seqüência de procedimentos do geral para o particular, onde o geral, isto é, a distribuição do manto de alteração regional, foi investigado por meio de técnicas de sensoriamento remoto e dados de poços tubulares na seguinte ordem:

1. Análise visual de imagens Landsat MSS, banda 7, no estudo morfotectônico.

2. Confecção de bloco-diagrama e mapa de tendência de espessura do manto de alteração, a partir de dados de espessura obtidos de poços tubulares perfurados para captação de água subterrânea pela Secretaria da Agricultura do Estado do Rio Grande do Sul.

$\mathrm{Na}$ área estudada, o manto de alteração é caracterizado, superficialmente, por zonas úmidas (exsudações) alternadas com zonas secas. Esse aspecto foi investigado em semidetalhe, por meio do processamento de imagens digitais no SIT1M-150 do CEPSRM (Centro Estadual de Pesquisas em Senspriamento Remoto e Meteorologia), em Porto Alegre. Foi utilizada uma imagem digital do TM-Landsat, correspondente à orbita 220 , ponto 80 , de $01 / 08 / 87$, com seis bandas espectrais reflectivas, para visualização do solo úmido e solo seco e também para estabelecer uma relação entre o valor das reflectâncias das áreas secas e úmidas.

A relação estabelecida pelo SITIM foi controlada por interpretação visual de fotografias aéreas (preto e branco, esc. 1:110.000, SA.C.S., 1975), onde se verificou a correspondência dos dados do produto da análise digital, com aqueles observados na análise visual ao estereoscópio.

As investigações de detalhe foram feitas no campo, em perfis previamente selecionados a partir de dados das imagens. A descrição dos perfis do manto de alteração foi feita nos setores de maior exposição, em cortes de estradas.

Foram descritas as características dos horizontes dos perfis, suas espessuras, variações laterais e relações com a topografia e geomorfologia.

MORFOTECTÔNICA As imagens Landsat, em pequena escala, são adequadas para a analise morfotectônica, entendendo-se este termo como estudo de formas do terreno com significado tectônico e regional (Gold 1980).

$\mathrm{O}$ advento das imagens orbitais abriu nova perspectiva para as investigações integradas do relevo com os processos deformacionais em escala regional, condicionantes, em parte, do estado atual da paisagem e, dentre os seus vários aspectos, da distribuição e espessura do manto de alteração, um dos objetivos estabelecidos para esta pesquisa.

Para tal, foram considerados a análise da rede de drenagem das bacias dos Rios Caí, Antas e parcialmente a dos Rios Pelotas e Sinos, os lineamentos de 20 ou mais quilômetros de extensão, os modelados de dissecação do relevo, observados e extraídos de imagens Landsat MSS na escala

\footnotetext{
* Departamento de Geodésia, Instituto de Geociências, Universidade Federal do Rio Grande do Sul, Avenida Bento Gonçalves, 9500, Caixa Postal 15001, CEP 91500, Porto Alegre, RS, Brasil

** Centro Estadual de Pesquisas em Sensoriamento Remoto e Meteorologia, Universidade Federal do Rio Grande do Sul, Avenida Bento Gonçalves, 9500, Caixa Postal 15004, CEP 91500, Porto Alegre, RS, Brasil
} 


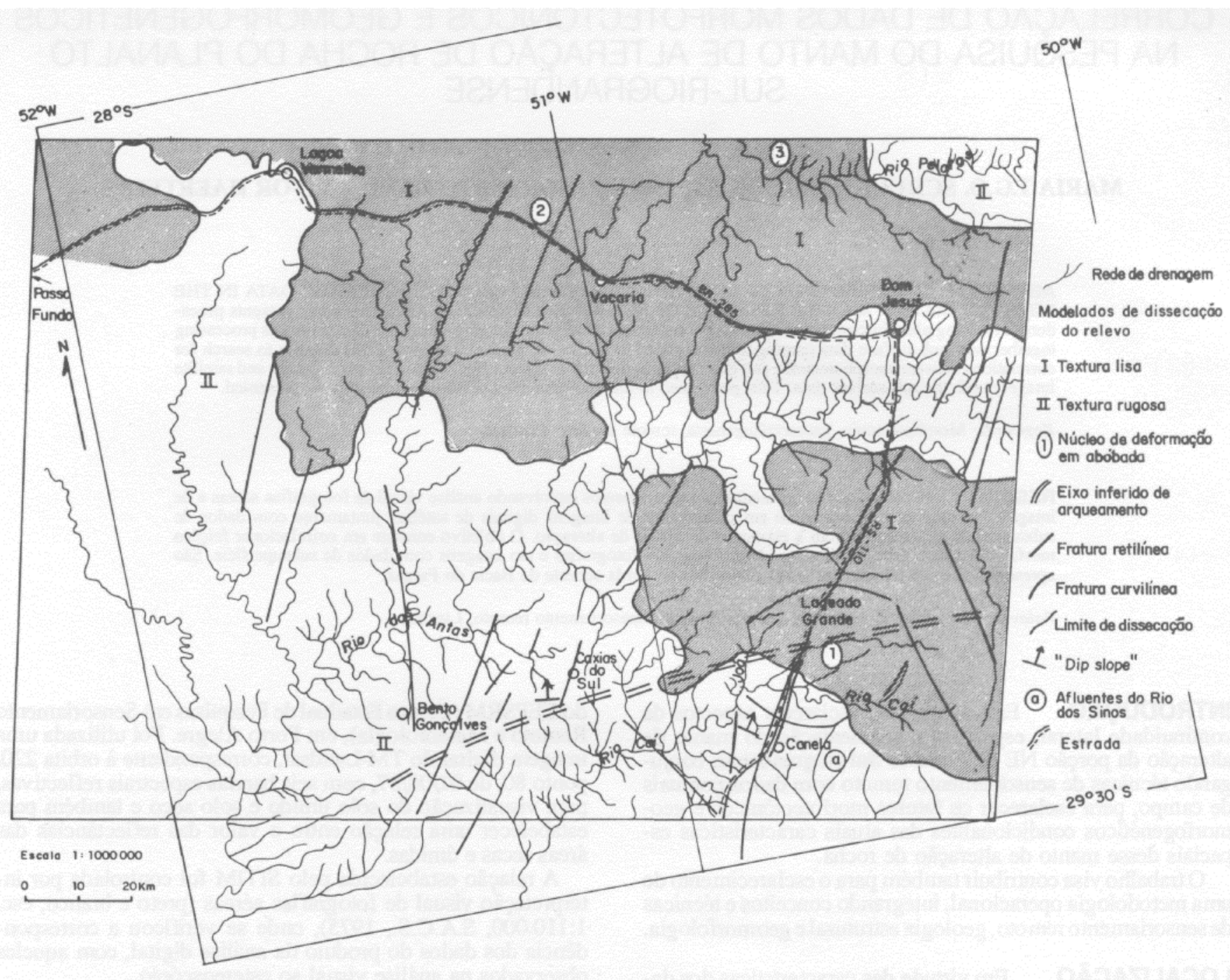

Figura 1 - Esboço morfotectônico a partir de imagens Landsat-MSS, escala 1:1.000.000 Figure 1 - Morphotectonic sketch based cm Landsat Image-MSS, scale 1:1,000,000

1:1.000.000 (Fig. 1), bem como dip slopes dos pacotes de lava extraídos de observação estereoscópica de aerofotos e comprovados com verificações de campo.

Em princípio, a análise partiu de um fato estabelecido (Lisboa et al 1985), ou seja, da existência de uma estrutura vulcano-tectônica elíptica com diâmetro de aproximadamente $32 \mathrm{~km}$, no Lageado Grande, e do pressuposto (Ab' Saber 1969): "Acreditamos, assim, que o planalto basáltico do nordeste do Rio Grande do Sul e sul-sudeste de Santa Catarina, além de ter sido uma grandiosa lente biconvexa de lavas, foi novamente deformado em abòbada, posteriormente aos aplainamentos iniciais durante as fases de soerguimento epirogênico mais importantes do Cretáceo e do Terciário".

Pela figura 1 , verifica-se que a estrutura vulcano-tectônica do Lageado Grande corresponde a um alto (1), a partir do qual os afluentes da margem esquerda do Rio das Antas, o Rio Caí e afluentes da margem direita do Rio dos Sinos, este fora dos limites da imagem analisada, definem um padrão de drenagem radial centrífugo.

No que se refere ao modelado de dissecação, o alto do Lageado Grande apresenta, na imagem analisada (Landsat-MSS, banda 7), textura lisa (I) e suas bordas, textura rugosa (II).

Os dois conjuntos descritos individualizaram um setor morfotectônico em que se configura a estrutura vulcano-tectônica do Lageado Grande como núcleo de deformação em arco com direção N70E, coincidindo com a direção do altiplano Caxias do Sul - Bento Gonçalves. Definido este setor, foram estabelecidos, em grandes traços, fatos relacionados ao estágio atual do relevo. Pelas fotografias aéreas, na escala 1:110.000, é constatada na região de Canela, para o topo do pacote de lavas em relação à base do conjunto, a observação feita por Ab' Saber (1969), ou seja, mergulho geral para N, NNE e $\mathrm{NNW}$, que é representado nas figuras le 3 .

Considerando o eixo inferido do arqueamento como linha divisória, foi verificada, a sul, uma dissecação intensa por canais curtos obseqüentes, afluentes da margem direita dos Rios Caí e Sinos, com a formação de duas escarpas de direção NE no altiplano Caxias do Sul - Bento Gonçalves e E-W no front do núcleo de deformação em abòbada do Lageado Grade. Os afluentes da margem esquerda do Rio das Antas são mais longos e produzem modelado de dissecação menos áspero do que os rios obseqüentes do front do núcleo de deformação.

A diferença de modelados de dissecação entre o núcleo de deformação em abòbada do Lageado Grande (1) (Fig. 1) e o altiplano Caxias do Sul é brusca a partir de uma escarpa retilínea com orientação NW que se situa $6 \mathrm{~km}$ a norte da junção do Rio Caí com o seu afluente Joá, onde a escarpa faz um cotovelo e muda a sua direção para NE. Portanto, além 
da deformação por arqueamento da superfície aplainada, morfoestruturas lineares podem ter influenciado na individualização dos modelados de dissecação.

$\mathrm{Na}$ relação entre os grandes fraturamentos e os canais de drenagem, é verificado que a configuração da drenagem foi principalmente condicionada pelas deformações por arqueamento, ocorrendo apenas uma adaptação parcial dos canais menores às fraturas, pois em vários pontos a rede de drenagem corta estas fraturas e é, portanto, em relação a estas, superimposta.

O Rio das Antas, principal canal de drenagem da área, possui, nas cabeceiras, direção geral E-W, infletíndo no seu curso médio para NE, sendo um dos limites do setor morfotectônico definido e analisado. Levanta-se a hipótese de seu desenvolvimento numa linha de fraqueza entre dois ou mais núcleos de soerguimento concomitantes, mas individualizados. Hipótese semelhante foi feita por Ab'Saber (1969) para as duas grandes calhas da Depressão Central, a Jacuí e a Ibicuí, que, segundo ele, desenvolveram-se em linhas de fraqueza, causadas pelo soerguimento em abóbada independentes do Escudo e Planalto.

COMPORTAMENTO REGIONAL DO MANTO DE ALTERAÇÃO DE ROCHA O estudo do comportamento regional do manto de alteração foi iniciado com a compartimentação morfotectônica a partir de imagens MSS-Landsat, banda-7, escala 1:1.000.000 (Fig. 1), pelas quais foram individualizados setores de textura lisa e textura rugosa.

Tais setores foram então relacionados a dados pontuais de espessura do manto de alteração, extraídos de perfis de poços perfurados para aproveitamento da água subterrânea. Os poços foram previamente arranjados num banco de dados de fácil consulta por computador com todas as informações pertinentes, como localização geográfica, dados geológicos e hidráulicos.

Com os recursos do banco de dados, foram selecionados poços situados dentro da área de interesse, junto com as informações necessárias para a construção, no computador, de mapas regionais que mostraram a tendência da espessura do manto de alteração (Fig. 2b), com a respectiva visualização tridimensional no bloco diagrama (Fig. 2a), utilizando-se o método de krigagem descrito detalhadamente por Pettinatti (1983) e Yamampto (1986).

Conforme as informações pontuais contidas nos poços, a espessura do manto de alteração na área varia de O a 29 m (Fig. $2 \mathrm{a}$ e $2 \mathrm{~b}$ ) e é correlacionável com as texturas evidenciadas nos produtos do sensoriamento remoto analisados, ressalvando as limitações impostas pela distribuição irregular e baixa densidade dos poços em relação à área abrangida.

Assim, evidencia-se uma tendência de pequenas espessuras do manto de alteração $(0-2 \mathrm{~m})$ nas áreas correspondentes às bacias dos Rios Pelotas, Caí e Antas, que, no bloco diagrama (Fig. 2a), estaria representada pelas superfícies mais elevadas, correlacionando-se com a textura rugosa identificada na figura 1 .

As áreas com espessuras medianas do manto de alteração (4 -10 m) (Fig. 2b) distribuem-se principalmente nos setores de textura Usa identificadas na figura 1.

As áreas de maiores espessuras do manto de alteração (10 - $29 \mathrm{~m}$ ) correlacionam-se com as zonas onde foram identificados lineamentos de mais de $20 \mathrm{~km}$ de extensão, com direções NE e N-S (Figs, 1 e 2b).

Os parâmetros observados permitem uma conclusão geral que relaciona os dados de espessura do manto de alteração com as estruturas e compartimentos do relevo, identificados nos produtos de sensoriamento remoto, associando as grandes espessuras com os fraturamentos, as espessuras medianas do manto de alteração com as áreas aplainadas, e as pequenas espessuras, distribuídas com maior freqüência nos terrenos com elevado grau de dissecação.

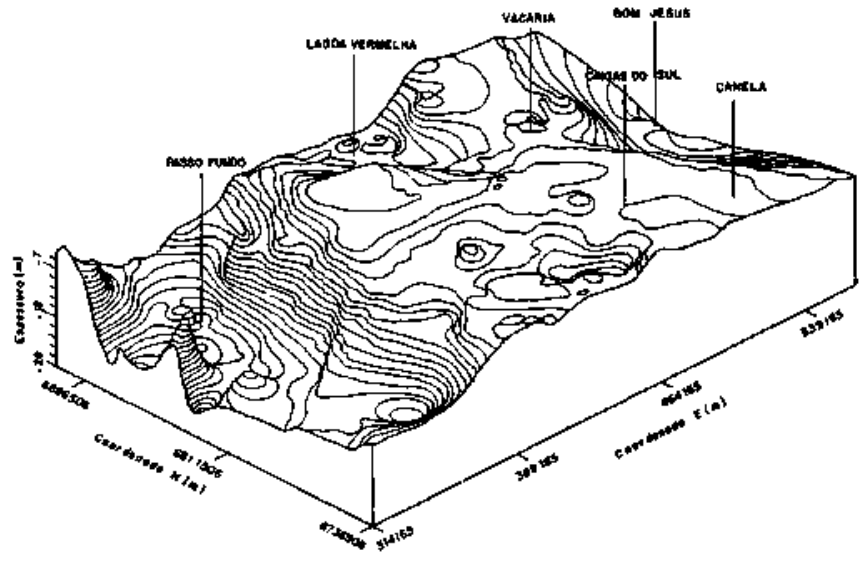

Figura 2 a - Bloco-diagrama da superfície basal do manto de alteração de rocha

Figure 2a - Diagram bloc of the basal surface of the alteration mande

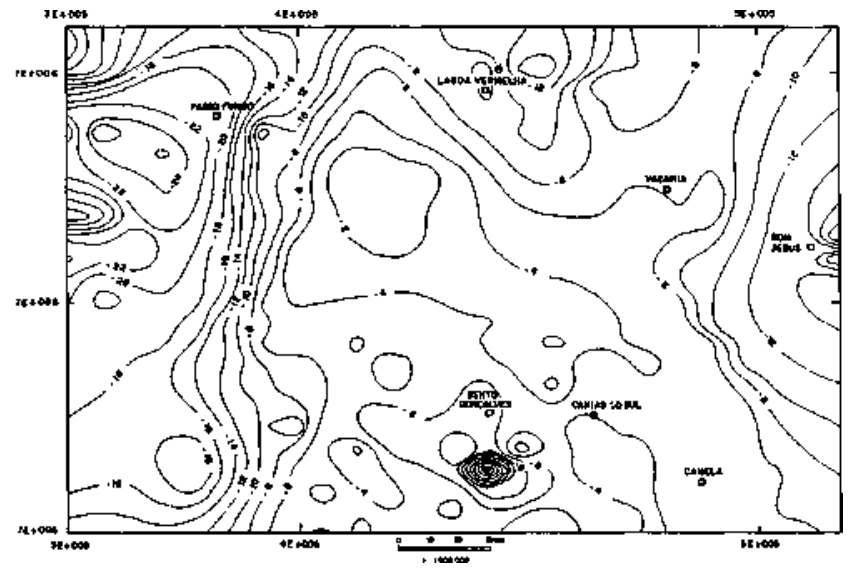

Figura 2 - Mapa de tendência da espessura do manto de alteração

Figure $2 \mathrm{~b}$ - Thickness trend of the alteration mantle

\section{GÉOMORFOLOGIA DO NÚCLEO DE DEFORMA- ÇÃO EM ABOBADA DO LAGEADO GRANDE No} entender dos autores, a paisagem atual do núcleo de deformação em abóbada do Lageado Grande resultaria da interação de processos vulcânicos, tectônicos e geomorfogenéticos, que atuaram em tempos pretéritos e ainda hoje continuam agindo.

A figura 3, que ilustra a discussão deste subtítulo, foi elaborada a partir da fotointerpretação de aerofotos na escala 1:110.000, contém dados altimétricos extraídos de cartas topográficas e é complementada com observações de campo. Essa figura caracteriza quatro compartimentos topográficos distintos na paisagem.

O nível $900-1.000 \mathrm{~m}$ é de pouca extensão lateral, restrito ao extremo NW da área, nas localidades do Morro do Chapéu e Coxilha de São Francisco de Paula. As formas do relevo são aplainadas, morros testemunhos de bordos festonados e retiíńnios.

O nível 900 - 960 m corresponde a relevos aplainados de bordos festonados ou retilíneos, descontínuos.

O nível de cotas 860 - $880 \mathrm{~m}$ é sulcado pela rede de drenagem atual, aí se localizando, entre outros, os Arroios do Porto Morto, Arroio Lava Pé e Arroio Morro Grande. Caracteriza-se por exsudações freáticas nas cabeceiras dos afluentes de primeira ordem, sendo que estas exsudações apresentam-se em fotografias aéreas como manchas cinzaescuro. $\mathrm{O}$ arranjo espacial da rede de drenagem pode ser classificado como angular (parcialmente controlado pelas fraturas do terreno, com exsudações freáticas nas fraturas e intersecções de fratura). Este compartimento topográfico 


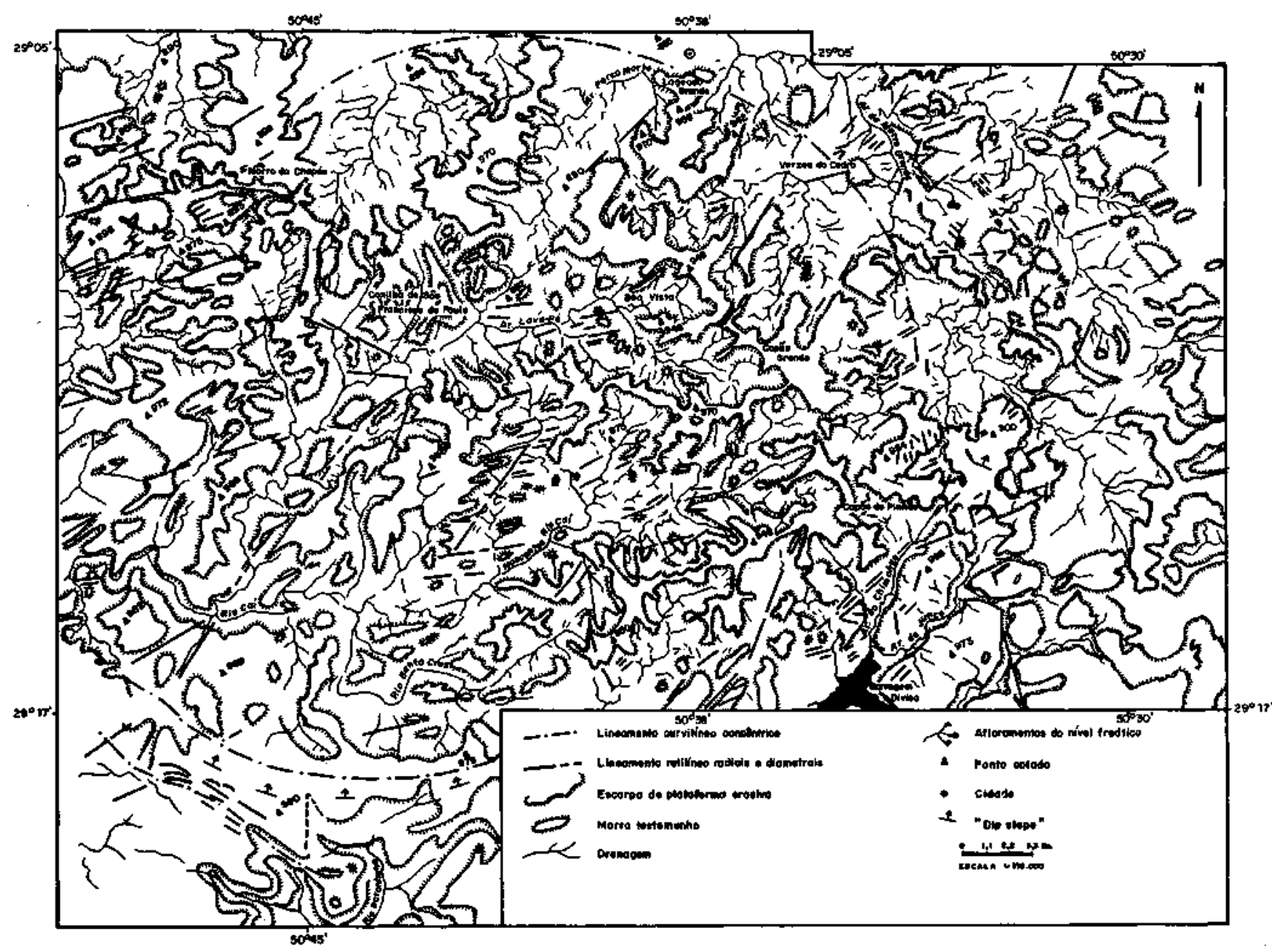

Figura 3 - Esboço geomorfológico da região do Lageado Grande, RS, a partir de interpretação de fotos aéreas 1:110.000 Figure 3 - Geamorphology of Lageado Grande, based on airphoto interpretation

corresponde aos "...vales de pouca declividade, em especial nas cabeceiras... e de largura incompatível com o tamanho atual destes canais." (Lisboa et al. 1985), que os autores denominaram de pedimentos.

O nível de cotas de aproximadamente 600 m coincide com vales retílineos e estreitos, com patamares de rocha ocorrentes ao sul da estrutura tectônico-elíptica do Lageado Grande, no Rio Paranhana.

A estrutura vulcano-tectônica elíptica do Lageado Grande situa-se no Planalto de Lavas do Rio Grande do Sul, de composição ácida, conforme mostra o mapa geológico elaborado pelo Projeto RADAM-Brasil, Folhas SH/SI-22/21.

A compartimentação topográfica anteriormente discutida apresenta quatro níveis distintos, aos quais se associam morros testemunhos em dois níveis, pedimentos vales com vertentes escalonadas (terraços de rocha).

A análise da rede de drenagem apresenta diversificação de tipos genéticos de cursos d'água (Fig. 3), na qual atenção especial foi dada aos cursos superimpostos. Como exemplo, tem-se o Arroio Porco Morto, que corre para NE, relacionado à inclinação da superfície topográfica mais antiga, anterior à exumação da estrutura vulcano-tectônica do Lageado Grande.

A drenagem superficial nasce em exsudações freáticas (banhados), especialmente as situadas acima do diâmetro E-W da estrutura, e não apresenta planícies aluviais.

A água subterrânea acumulada nas fraturas, especialmente na intersecção de fraturas, aflora, nestes locais, dentro da estrutura vulcano-tectônica e favorece o intemperismo.
Essas condições se estendem também para as proximidades leste, norte e oeste. Nas nascentes do Rio Paranhana (Fig. 3), as condições de circulação da água se modificaram. Aí, os vales em "V" profundos com vertentes escalonadas formam terraços de rocha e funcionam como calhas de escoamento da água que permeia rapidamente pelas fissuras, impedindo a acumulação e dificultando a formação de um manto de intemperismo mature (taxa de erosão maior que a taxa de intemperismo), resultando em freqüentes exposições de rocha nua, perfis incompletos de solo, inclusive decapitação do solo, depósitos de tálus com grande mobilidade e escorregamentos.

Sobre a morfologia das vertentes, os níveis 900 - $960 \mathrm{~m} \mathrm{e}$ 960 - $1000 \mathrm{~m}$, correspondentes a morros testemunhos, apresentam superfícies de aspecto kárstico e vertentes retilíneas.

O nível $860 \mathrm{~m}$, correspondente a pedimentos, apresenta vertentes côncavas e de pouca amplitude.

Considerando as descrições da estrutura superficial da paisagem, evidenciadas no estereomodelo e confirmadas em observações de campo, é possível integrar as feições descritas para o Lageado Grande (geomorfológicas e estruturais) e avançar a sua denominação para o termo boutonnière que "É um tipo de relevo estrutural que pressupõe arqueamento em abóbada, uma superimposição hidrográfica no eixo central do domo e uma longa história erosiva, suficiente para ocasionar evacuação de um grande estoque de massas rochosas, anteriormente constituintes de sua própria estrutura" (Ab'Saber 1988). 
Para entender os processos morfodinâmicos que esculpiram a paisagem atual e, conseqüentemente, o zoneamente do manto de alteração, será examinado o papel dos agentes endógenos e exógenos ao longo do tempo, por meio de suas "marcas" na superfície estudada.

$\mathrm{O}$ estudo morfotectônico evidenciou a estrutura elíptica do Lageado Grande e apontou para uma origem vulcano-tectônica relacionada às condições originais de extravasamento do magma e com movimentos verticais da crosta. A existência de cursos d'agua superimpostos à estrutura denota que o soerguimento que promoveu o aparecimento das fraturas curviüneas, na superfície, é posterior aos aplainamentos da chamada superfície de Vacaria (Ab'Saber 1969), cujos resíduos preservados e basculados constituem as compartimentações topográficas 900 - $960 \mathrm{~m}$ e 960 - $1000 \mathrm{~m}$, descritas anteriormente, que se dispõem concentricamente a oeste da fratura curvilínea (Fig. 3). O pacote de lavas, no local, está inclinado para NW, apresentando mergulho concordante àquele reportado por Ab' Saber (1969), de inclinação das estruturas basais do pacote basáltico dominantemente de SSE para NNW e oposto ao da superfície de aplainamento, materializada pelos níveis topográficos 900 - $960 \mathrm{~m}$ e 960 - $1000 \mathrm{~m}$, que mergulha, regionalmente, para sul-sudoeste.

\section{EFICIÊNCIA DAS TÉCNICAS DE SENSORIAMENTO REMOTO NO ESTUDO DO MANTO DE ALTERACÃO}

Elemento importante na evolução do manto de alteração espesso, no clima atual, são as exsudações freáticas associadas a fraturas, em especial onde ocorrem intersecções de fraturas nos largos vales desenvolvidos por processos de pedimentação em época passada.

Nesse setor, efetuou-se um estudo de semidetalhe por meio de pesquisa das exsudações freáticas por processamento de imagens digitais. Para essa finalidade, foi utilizado um sistema computadorizado denominado de SITRIM (Sistema de Tratamento de Imagens) desenvolvido pelo Instituto Nacional de Pesquisas Espaciais (INPE) e disponível no Centro Estadual de Pesquisas em Sensoriamento Remoto e Meteorologia (CEPSRM) da Universidade Federal do Rio Grande do Sul. Detalhes sobre o sistema SITIM podem ser encontrados no manual desse sistema (Engespaço 1988).

A pesquisa limitou-se a setores da Boutonnière no Lageado Grande, dos quais o CEPSRM dispunha de fitas magnéticas, e buscou definir as bandas individuais, bem como as composições coloridas envolvendo mais de uma banda, mais adequadas à identificação visual, e, auxiliada por computador, de áreas de exsudações freáticas.

As áreas de exsudações freáticas apresentam vegetação mais densa do que as áreas circunvizinnas, gerando, normalmente, pixels "puros" (vegetação unicamente). As áreas circunvizinnas, entretanto, apresentam teor de umidade muito mais baixo, com vegetação menos densa. Essas regiões geram pixels "mistura" envolvendo vegetação e solo exposto.

Os dados utilizados consistem das seis bandas espectrais reflectivas (visível, infravermelho próximo e infravermelho médio) disponíveis no sistema Landsat-TM. Neste trabalho, foi utilizada uma fita correspondente à órbita 220 , ponto 80 , obtida em 1 de setembro de 1987, cobrindo o Planalto Nordeste do Estado do Rio Grande do Sul.

Nas fitas, o valor associado a cada pixel nas diversas bandas espectrais é expresso em contadores digitais ( 8 bits/pixel no sistema Landsat-TM).

Esses valores carecem, entretanto, de sentido físico direto. Por essa razão, alguns autores (Robinove 1982, Markham \& Baker 1986) sugerem a conversão dos contadores digitais em grandezas com significado físico direto (radiância ou reflectância). Dessa forma, a imagem original foi transformada de contadores digitais para reflectâncias, seguindo o roteiro descrito em Shimabukuro (1987). Para essa trans- formação, foi utilizada a "Rotina Reflete", disponível no sistema SFTIM. Os valores de reflectância (0 a 1) são expressos em uma escala discretizada de 256 valores, para possibilitar o tratamento pelo SITIM.

Os valores da reflectância, assim calculados, correspondem a valores "no topo da atmosfera", isto é, afetados pela influência atmosférica (atenuação e espalhamento de radiação).

Para o processo de análise visual, foram consideradas inicialmente as seis bandas individuais. Na cena, foram selecionadas duas áreas típicas: uma de exsudação freática e outra de área seca. Em cada uma das áreas foram anotados os valores de reflectância para uma amostra de 25 pixels.

Com esses dados, busca-se estabelecer um critério que permita hierarquizar as seis bandas reflectivas, conforme a habilidade de discriminar áreas de exsudação freática. $\mathrm{O}$ critério adotado consistiu da relação entre o valor médio da reflectância das áreas secas em relação ao das áreas de exsudação freática.

A energia registrada pelo sensor vem afetada por dois fatores, um multiplicative (a) e outro aditivo (b):

$\mathrm{Rm}=\mathrm{a} \mathrm{R}+\mathrm{b}$

onde: $\mathrm{R}=$ reflectância do alvo

onde: $\mathrm{Rm}=$ reflectância efetivamente medida pelo sensor.

O fator aditivo (b) resulta basicamente do espalhamento atmosférico e deve ser corrigido por alguns dos métodos disponíveis. O fator multiplicative (a) pode ser causado por fatores diversos, como variações na irradiância devido ao efeito do relevo, e outros (Slater 1980). Alvos situados fisicamente próximos entre si na imagem, e, no geral, semelhantes no terreno, serão afetados por um fator multiplicative praticamente idêntico, que pode, portanto, ser corrigido após a eliminação do fator aditivo, pela razão entre as respostas de ambos os alvos. Por esse motivo, foi selecionada a razão entre as reflectâncias medidas e corrigidas da contribuição atmosférica como parâmetro de trabalho.

Uma relação apresentando valor unitário significa poder discriminatório nulo. Conforme o valor dessa relação afasta-se da unidade, aumenta a capacidade da respectiva banda espectral em separar as áreas secas das áreas de exsudação freática.

Os resultados estão relacionados na tabela 1 .

Tabela 1 - Valores médios da reflectância e da razão entre as reflectâncias de áreas secas e de exsudações freáticas Table 1 - Reflectance mean values and ratios between dry and freatic exsudation areas

\begin{tabular}{|c|c|c|c|}
\hline DANDA & $\begin{array}{l}\text { VALOR MÉDIO } \\
\text { AREA SECA }\end{array}$ & $\begin{array}{l}\text { VALOR MEOOOO } \\
\text { ÁREA ÚMIDA }\end{array}$ & $\operatorname{Aa}=x_{0}$ \\
\hline $\mathbf{T}$ & 29.28 & 23.79 & 1.2383 \\
\hline 8 & 95.40 & 76.60 & 1.2147 \\
\hline 3 & 39.52 & 30.32 & 1.1716 \\
\hline 2 & 27.32 & 23. & 1.1440 \\
\hline $\mathbf{1}$ & 67.92 & 54.60 & 1.0834 \\
\hline
\end{tabular}

Os valores assim obtidos concordam com as conclusões obtidas visualmente. As bandas sete, cinco e três apresentam os melhores resultados. A banda quatro apresenta-se em uma posição intermediária, enquanto as bandas dois e são menos favoráveis. Esses resultados podem ser interpretados pelas curvas de resposta espectral da vegetação, do solo e 


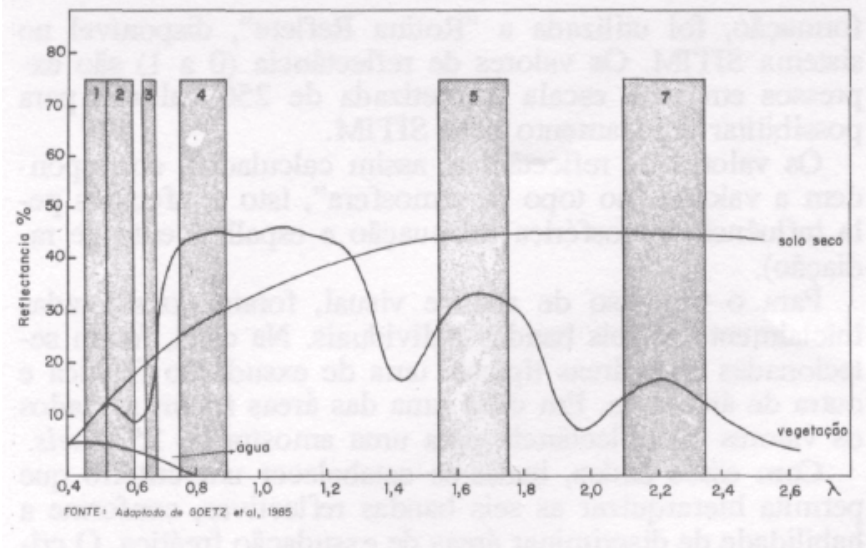

Figura 4 - Curvas de reflectância da vegetação e solo seco e água, e localização das bandas espectrais reflectivas do sistema Landsat-TM

Figure 4 - Reflectance curves of vegetation \& dry soil \& water and reflective spectral band localization of Landsat-TM

da água. As áreas de exsudação freática são cobertas por vegetação mais densa, com bom suprimento de água.

As regiões circunvizinhas são cobertas por uma vegetação menos densa, crescendo em um solo mais seco. Como resultado, os pixels que cobrem essa região são pixels "mistura", envolvendo vegetação e solo exposto.

As bandas TM-5 (1,55 $\mu \mathrm{m}$ - 1,75 $\mu \mathrm{m})$ e TM-7 $(2,08 \mu \mathrm{m}$ $2,35 \mu \mathrm{m})$ estão localizadas no infravermelho médio, entretrês fortes bandas de absorção de água $(1,4 \mu \mathrm{m}, 1,9 \mu \mathrm{m}$ e 2,6 um). Essas bandas espectrais são fortemente influenciadas pelo conteúdo de água nas folhas de vegetação. É fato bem conhecido que um menor conteúdo de água nas folhas aumeta substancialmente a reflectância da vegetação, em toda a parte reflectíva do espectro, mas com maior intensidade no infravermelho médio. Aqui, esse aumento é verificado não somente nos comprimentos de onda das bandas de absorção da água, mas também nas regiões do espectro localizadas entre essas bandas, pelo efeito conhecido como carryover (Swain \& Davis 1978),

As áreas de exsudação freática geram pixels correspondentes a uma densidade de cobertura de vegetação e água. Conseqüentemente, a reflectância nessa região é bastante inferior a das áreas vizinhas, cuja vegetação reflete mais energia por possuir menor conteúdo de água nas folhas. A contribuição do solo exposto (pixels "mistura") nessas áreas contribui também para o aumento da reflectância. Nessa região, o solo é predominantemente argiloso, raso, mesclado com rochas aflorantes, resultando, portanto, em reflectância alta.

Um bom contraste para delimitação de áreas úmidas foi também obtido na banda TM-3 $(0,63 \mu \mathrm{m}-0,69 \mu \mathrm{m})$. Essa banda está localizada no pico de absorção da clorofila. Novamente aqui, a vegetação mais densa, existente nas áreas de exsudação freática, resulta em maior absorção da radiação eletromagnética. A esse fato soma-se, ainda, a maior reflectância das parcelas do solo exposto nos pixels "mistura" das regiões secas.

As características espectrais do solo e da vegetação explicam, igualmente, os resultados obtidos com as demais bandas do sistema TM.

No infravermelho próximo (banda quatro), a alta reflectância da vegetação e do solo exposto tende a diminuir o contraste entre as duas áreas, resultando no desempenho apenas regular apresentado por essa banda.

Os piores resultados são apresentados pelas bandas TM $1(0,45 \mu \mathrm{m}-0,52 \mu \mathrm{m})$ e TM - $2(0,52 \mu \mathrm{m}-0,60 \mu \mathrm{m})$.
Nessa região do espectro, tanto os pixels "puros" (vegetação) das áreas úmidas, quanto os pixels "mistura" das áreas secas, apresentam reflectância baixa, resultando em um baixo contraste entre essas áreas.

Os resultados obtidos pela combinação de três bandas espectrais (visual e por computador) estão de acordo com os obtidos para as bandas individuais. A identificação das áreas de exsudação freática foi realizada visualmente pela composição colorida de três bandas. As mesmas três bandas foram também utilizadas no sistema SITIM para classificar os temas de interesse.

Nesse caso, foi utilizado o método de classificação temática por máxima verossimilliança gaussiana. Esse método encontra-se amplamente discutido na literatura, como por exemplo em Richards (1987). As amostras, para estimar as estatísticas necessárias, foram obtidas da própria imagem, utilizando áreas conhecidas no terreno como pertencentes às três classes de interesse (Fig. 5).

Coerentemente com a análise anterior, a combinação das bandas três, cinco e sete foi a que melhor resultado apresentou. As combinações que apresentaram condições fracas ou regulares para identificação visual das áreas de exsudações freáticas são aquelas que incluem apenas uma das bandas adequadas $(3,5$ e 7$)$ ou nenhuma delas.

DESCRIÇÃO ESQUEMÁTICA DOS PERFIS DE ALTERAÇÃO As verificações de campo confirmaram as observações preliminares feitas nas imagens sobre a compartimentação topográfica da paisagem, que consta dos seguintes elementos: pediplanos (morros de topo aplainado), pedimentos erosivos (vales largos em forma de "U", com exsudações freáticas esparsas), vales em "V", correspondentes à drenagem atual, embutidos nos pedimentos.

Os cortes de estrada, especialmente na BR-285, que liga Bom Jesus a Passo Fundo, e a Estrada Estadual que liga Bom Jesus a Canela, expuseram variados perfis de alteração, todos cobertos por uma camada de solo atual (A), cor escura, espessura variando entre $0,1 \mathrm{~m}$ e $0,5 \mathrm{~m}$. Abaixo desse horizonte "A" ocorrem diferentes tipos de horizontes. Em alguns perfis, principalmente entre Vacaria e Lagoa Vermelha (Fig. 1), aparece abaixo do horizonte "A" um nivel vermelho, de espessura variável entre $\mathrm{O}$ e $2 \mathrm{~m}$, friável, argiloso, sem estruturas evidentes. Abaixo desse horizonte vermelho, e quando este ocorre, é comum o aparecimento de Unhas de pedra. Os fragmentos são de tamanho variado, de alguns centímetros até $0,5 \mathrm{~m}$, cobertos por uma película amarelada de óxidos de ferro e de alumínio com núcleo correspondente a rocha fresca. Esta Unha de pedra está balizando o horizonte inferior de saprólito e constitui uma superfície irregular, com concavidades preenchidas pelo material do horizonte vermelho.

O saprólito apresenta cores amarelas, estruturas do tipo boulders, blocos de rocha alterada em camadas com núcleo de rocha fresca ou núcleo alterado, atravessados por veios brancos de material argiloso, e superpõe-se sempre às rochas efusivas.

Em alguns cortes da Rodovia BR-285, entre Bom Jesus e Lagoa Vermelha, é visível a seqüência completa dos horizontes descritos (Fig. 6).

Considerando que os solos resultam da transformação das rochas sob a ação de um tipo de clima por um determinado período de tempo, Krauskopf (1972) assinala que "a divisão mais importante é entre solos de regiões úmidas e solos de regiões áridas". Os primeiros caracterizam-se por uma concentração de óxidos de ferro e de alumínio no horizonte "B". $\mathrm{Na}$ transição de clima úmido para seco, a evolução do solo é reduzida, a lixiviação diminui e predominam os processos de intemperismo físico.

Essa alternância climática, ao longo do tempo geológico, imprime diferentes horizontes no manto de alteração de rocha, que na área estão preservados nos perfis atuais. 


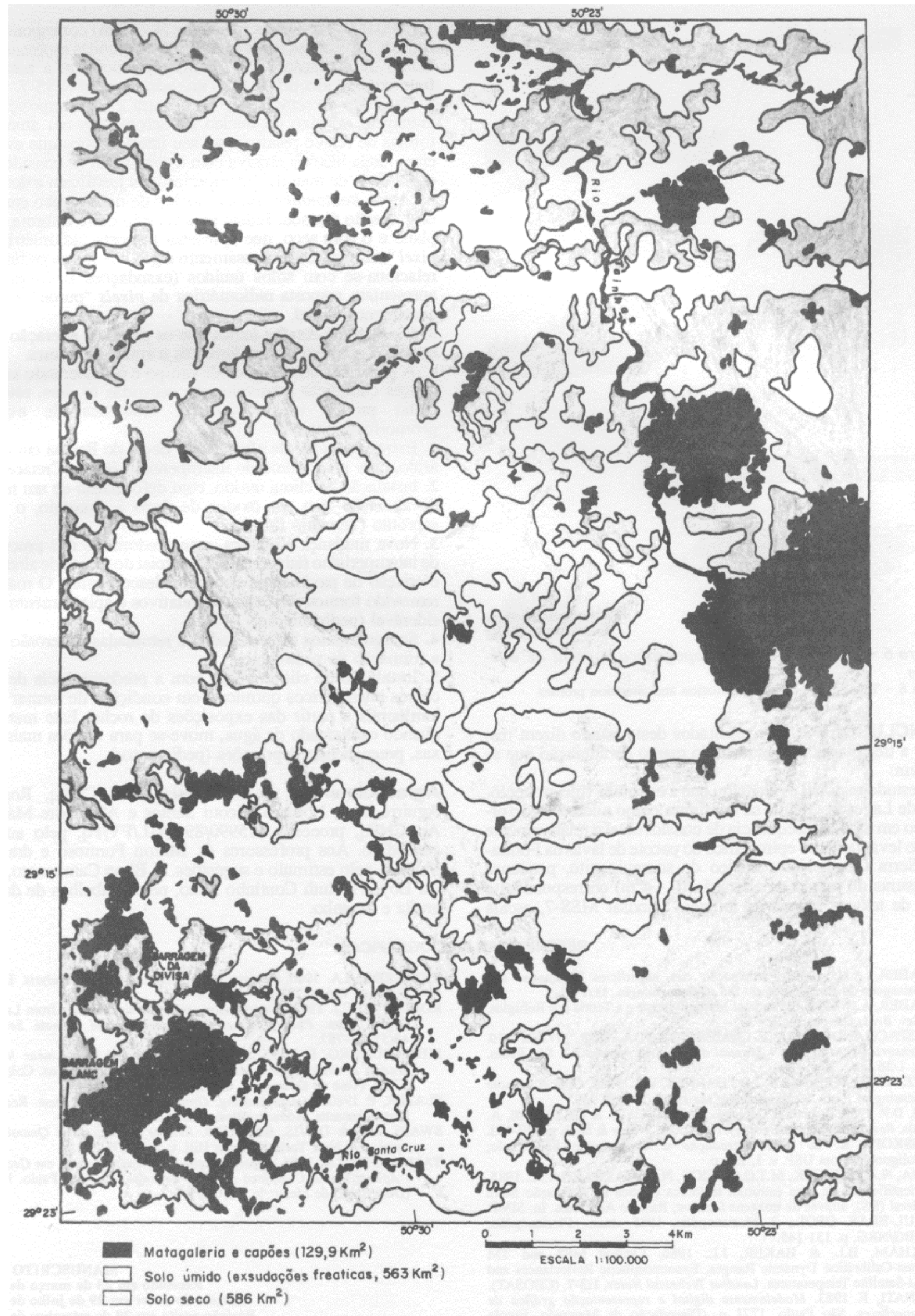

Figura 5 - Classificação temática por máxima verossimilhança 

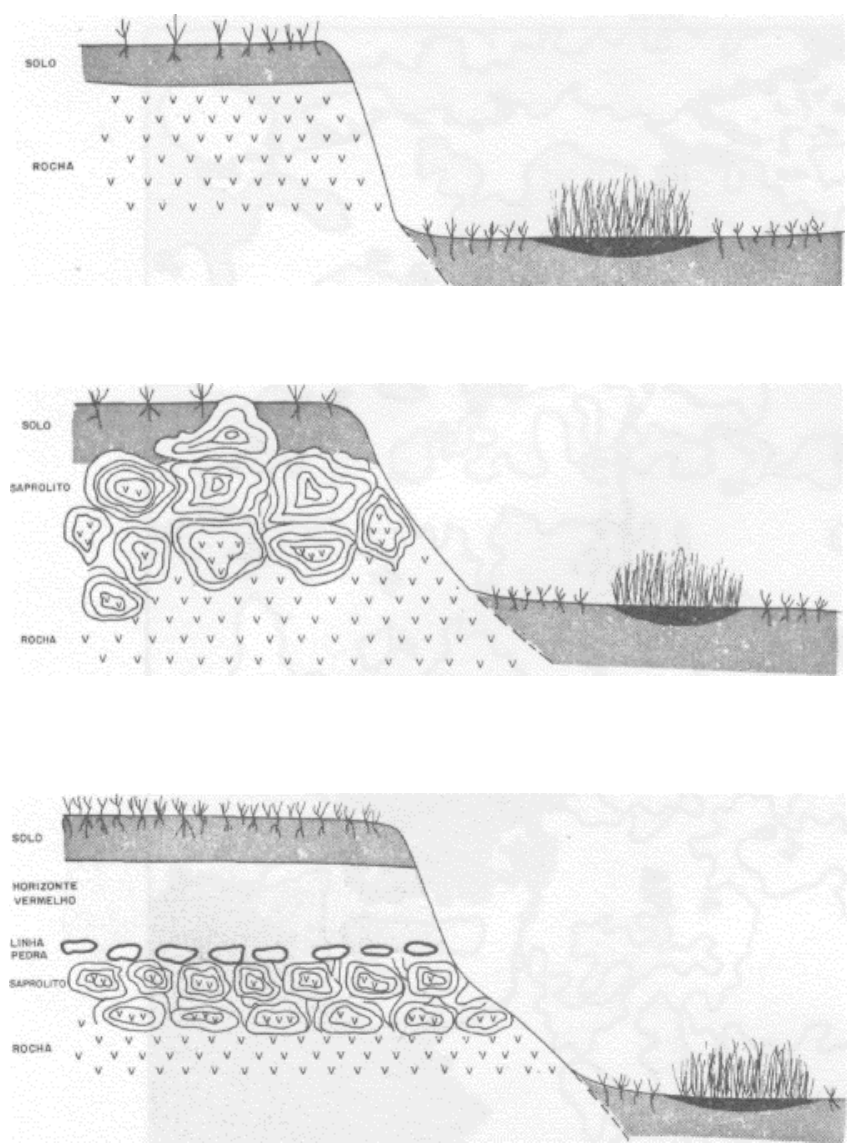

Figura 6 - Compartimentação topográfica e perfil de alteração

Figure 6 - Topographic compartimentation and alteration profiles

CONCLUSÕES Os resultados deste estudo dizem respeito a três etapas de pesquisa do manto de alteração que se seguem:

1.O estudo regional evidenciou que a estrutura vulcano-tectônica de Lageado Grande se configura como núcleo de deformação em arco, conseqüência de considerável e relativamente rápido levantamento epirogênico do pacote de lavas da Formação Serra Geral. Neste núcleo de soerguimento, pequenas espessuras do manto de alteração $(0-4 \mathrm{~m})$ correspondem à zona de textura rugosa na imagem Landsat MSS-7, escala
1:1.000.000; espessuras medianas (4 - $10 \mathrm{~m})$ correspondem à zona de textura lisa na imagem MSS-7; grandes espessuras do manto de alteração $(10-20 \mathrm{~m})$ correspondem a zonas de fraturamento identificadas na imagem Landsat MSS-7.

2. O estudo de semidetalhe demonstra a superimposição da drenagem no eixo do núcleo de deformação em arco e as formas de relevo residuais no seu interior, fatos que evidenciam longa história erosiva com a evacuação de considerável quantidade de material intemperizado, e justificam a denominação de Boutonnière para o núcleo de deformação em arco do Lageado Grande. Existe uma relação entre a forma pediplano e o solo seco, que apresenta resposta radiométrica de pixel "mistura" no processamento digital. A forma pedimento relaciona-se com solos úmidos (exsudações freáticas) que apresentam resposta radiométrica de pixels "puros" no processamento digital.

3. O estudo de detalhe indica que os perfis de alteração mais espessos ocorrem nos pedimentos e zonas de fratura.

A partir das observações de campo e considerando as mudanças climáticas possivelmente ocorridas na área, este trabalho propõe uma seqüência hipotética de eventos geomorfoclimáticos:

1. Extravasamento de efusivas da Bacia do Paraná em clima árido, com predomínio de intemperismo físico (Cretáceo).

2. Instalação de clima úmido, com deformação de um manto de alteração rico em óxidos de ferro e alumínio, o atual saprólito (Terciário Inferior).

3. Nova mudança climática, com predomínio dos processos de intemperismo físico, remoção parcial do manto de alteração e criação de pavimentes detríticos descontínuos. O material removido formou depósitos correlativos e aplainamento considerável (pediplanação).

4. Soerguimentos diferenciados e retomadas de erosão com a formação de pedimentos.

5. Instalação de clima úmido com a predominância de processos intempéricos químicos, em condições de formar argilominerais a partir das exposições de rocha. Este material, quando encharcado de água, move-se para regiões mais baixas, preenchendo depressões (pedimentos).

Agradecimentos Aos bolsistas do CNPq, Rogério Aguirre Dias, Homero Nicotti Santos e Alexandre Mansur. Ao $\mathrm{CNPq}$, processo 415990/89-0/GL/FV/Pq, pelo auxílio concedido. Aos professores dr. Milton Formoso e dra. Ida Valeton, pelo estímulo e sugestões. A Élton Campanaro, Flávia Boyen e Ruth Coutinho Pinto, pelos trabalhos de datilografia e desenho.

\section{REFERÊNCIAS BIBLIOGRÁFICAS}

AB'SABER, A.N. 1969. Participação das superfícies aplainadas nas paisagens do Rio Grande do Sul. Geomorfologia, 11:1-17.

AB'SABER, A.N. 1988. O Pantanal Matogrossense e a Teoria dos Refúgios. Rev. Bras. Geogr., 50(2):9-57.

ENGESPAÇO INDUSTRIA E COMÉRCIO LTDA. 1988. SITWM 150 Sensoriamento Remoto - Manual do Usuário. Versão 2.2. São Paulo. p. 1-36.

GOETZ, A.F.H.; WELLMAN, J.B.; BARNES, W.L. 1985. Optical Remote Sensing of Earth. Proceedings of the IEEE, 73:950-969.

GOLD, D.P. 1980. Structural Geology. In: SIEGAL, B. \& GILLESPEE, A. eds. Remote Sensing in Geology. New York, Willey \& Sons. p. 419-483.

KRAUSKOPF, K. B. 1972. Introdução à Geoquímica. São Paulo, Polígono/Editora USP. v. 1, 294 p.

LISBOA, N.A.; SCHUCK, M.T.G.O.; EICK, N.C.; CARRARO, C.C. 1985 Identificação de uma estrutura tectônica elíptica na Formação Serra Geral (RS), através de imagens Landsat, Radar e Aerofotos. In: SIMP. SUL-BRAS. GEOL., 2. Florianópolis, 1985. Atas... Florianópolis, SBG/NRG. p. 131-145.

MARKHAM, B.L. \& BAKER, J.L. 1986. Landsat MSS and TM Post-Calibration Dynamic Ranges, Exoatmospheric Reflectances and At-Satellite Temperatures. Landsat Technical Notes, 1:3-7. (CEOSAT).

PEITINATI, F. 1983. Modelamento digital e representação gráfica de superficies. São Paulo. 1771 p. (Dissertação de Mestrado, Escola Politécnica/USP).
RICHARDS, S.A. 1986. Remote Sensing Digital Image Analysis. Berlin, Springer Verlag. $281 \mathrm{p}$.

ROBINOVE, C.J. 1982. Computation with physical values from Landsat Digital Data. Photogrammetry Engineering and Remote Sensing, 48(5): 781-787.

SHTMABUKURO, E. 1987. Shade Images Derived from Linear Mixing Models of Multispectral Measurements of Forested Areas. Colorado. 274 p. (Tese de Doutorado, Colorado State University).

SLATER, P. 1980. Remote Sensing, Optics and Optical System. Reading. Massachusetts, Addison-Wesley ed. $515 \mathrm{p}$.

SWAIN, P.H. \& DAVIS, S.M. 1978. Remote Sensing: The Quantitative Approach. New York, McGraw Hill. v. 2, p. 275-271.

YAMAMOTO, J.K. 1986. Representações gráficas espaciais em Geologia - Aplicações no Complexo Alcalino de Anitapólis. São Paulo. 176 p. (Dissertação de Mestndo, IG/USP).
MANUSCRITO A652

Recebido em 23 de marco de 1990 Revisão do autor em 29 de julho de 1991 Revisão aceita em 20 de setembro de 1991 